\title{
Multimedia of Chemistry Enrichment in Colloidal Systems for Vocational High School Students
}

\author{
Miarti Khikmatun Nais ${ }^{1 *}$ \& Endang Dwi Siswani ${ }^{2}$ \\ ${ }^{1}$ Study Program of Chemistry Education, Graduate School, Yogyakarta State University, Indonesia \\ ${ }^{2}$ Department of Chemistry Education, Yogyakarta State University, Indonesia \\ *Corresponding author: E-mail: miarti.kn@gmail.com
}

\begin{abstract}
This research was conducted to develop the multimedia of colloidal systems as an enrichment media for vocational high school students in chemistry class and to know the quality of the multimedia. This was a research and development study. Developmental procedures used in this research were adopted from Borg and Gall development procedures consisting of six phases including: collecting information, planning, developing the preliminary form of the product, validating and revising the product, assessing the product, and revising final product. The products were validated by one content expert and one media expert and reviewed by three peer reviewers. The advises from the experts and the peer reviewers were used to improve the initial product. The assessment of the product was carried out by five reviewers based on six aspects of the criteria, included: content feasibility, language, visual-display of media, audiodisplay of media, media programming, and expediency of the media. The product assessment data were analyzed by categorizing the score into ideal rating category. In general, the multimedia assessment score was included in the category of very good category. Analysis on each aspect shows that content feasibility, media programming, and expediency of the media aspects was included in the very good category, while language, visual-display of media, audio-display of media aspects included in the good category. These results indicatated that the products were ideal as an enrichment media of colloidal systems for vocational high school students.
\end{abstract}

Keywords: research and development, enrichment multimedia, colloidal systems

\section{INTRODUCTION}

Chemistry is a very interesting because it is related to everyday life. In Indonesian vocational high school, chemistry is a subject of interest groups taught only in four areas of expertise including technology and engineering, health, agribusiness and agrotechnology, fisheries and agriculture [1]. Chemistry subject in vocational school is given only an hour and a half per week [1], so the material received is limited. Enrichment media that can be used at school and outside school is necessary to enrich knowledge of vocational students. Besides, today's learning should be student-centered and students should actively seek out information from various learning resources. The presence of enrichment media will help student to meet the learning resources and can be used for self-study.

Learning motivation of vocational school students tend to be lower than senior high school students [2]. Material meaning is one of the factors of low interest of students in learning chemistry [3]. Vocational students are more interested in learning chemistry when they feel chemistry material is relevant to their field [4]. Therefore, it is necessary to develop a material which relevant to their vocational field to increase the students' learning motivation in vocational school students.

Multimedia is a combination of text, graphics, animation, video, and sound that can display information, messages, or learning content [5]. Multimedia is very suitable as a chemistry enrichment media, because it does not only display text and images, but also displays animations, videos and sounds that can visualize abstract concepts of chemistry to be more concrete. In chemistry class multimedia has many advantages; 
(1) it is able to visualize objects that are very small and invisible to the eye, (2) it can presenting complex or dazzling events, (3) it can help presenting very large or very distant objects, and (4) it can increase attraction and attention [6]. Learning using multimedia will be more effective because of the animation and narration will transfer information better than word alone and static image [7, 8]. Furthermore, the use of multimedia instruction increase students' learning motivation [9].

Colloidal system is one of important subject in chemistry. Many of the products around us apply the principle of colloidal system, besides the colloidal system is also applied in various fields, such as health, agriculture, and industry. Unfortunately, most colloidal systems materials tend to be theoretical and quite abstract. The use of multimedia can help visualize these abstract materials become more concrete. Previous study found that students who received multimedia-based instruction that emphasized the molecular state of chemicals outperformed students from the regular instruction group in terms of the resulting test scores and the ease with which they could represent matter at the molecular level [10]. This research, accordingly, was conducted to develop the multimedia of colloidal systems as an enrichment media for vocational high school students in chemistry classrooms and to know the quality of the multimedia.

\section{METHODS}

This was a research and development study. This research used procedural development model. Developmental procedures used in this research were adopted from Borg and Gall development procedures consisting of six phases including: collecting information, planning, developing the preliminary form of the product, validating and revising the product, assessing the product, and revising final product [11].

Information colleting was conducted by literature review, and interview with some chemistry teachers of vocational school. The information obtained was used as a consideration for media development planning. Planning phase was done by arranging design and story board of multimedia that would be developed. The multimedia was developed using Adobe Flash Professional CS 6 and other supporting software. Initial product of multimedia was validated by one content expert and one media expert, and also was reviewed by three peer reviewer. The suggestions from content expert, media expert, and peer reviewers were considered to revise the initial product. After that, the multimedia was assessed by five chemistry teachers of vocational school. The teachers came from three different types of vocational school that was technology and engineering, health, and agriculture. The data obtained was used to evaluate the quality of the multimedia and improve the final product.

The assessment instrument used in this research was questionnaire and open suggestion sheet. The questionnaire was using five points of Likert scale (very good to very poor). The questionnaire was adapted from Angelina [12] and Susanto [13] instruments which was tailored to the EMPI (Evaluation of Multimedia Pedagogical and Interactive) criteria. The instrument consists of six aspects of the criteria, including: content feasibility, language, visual-display of media, audio-display of media, media programming, and expediency of the media. These aspects were translated into 26 point indicators.

There are two types of data in this research: data of development process and multimedia quality data. The data of multimedia development process was obtained from the suggestion of content expert, media expert, and three peer reviewers whose input were considered to improve the initial product. Meanwhile, multimedia quality data obtained from the assessment of five chemistry teachers of vocational high school as reviewers. Data of development process were analyzed qualitatively as consideration to improve multimedia. Meanwhile, the multimedia quality data were analyzed by categorizing the scores into five categories (very good to very poor) based on the ideal rating category [14]. The ideal rating category can be seen in Table 1 . 
Table 1 The Ideal Rating Category

\begin{tabular}{|c|c|c|}
\hline No. & Score Range & Category \\
\hline 1. & $\mathrm{Xi}+1,8 \mathrm{SBi}<\overline{\mathbf{X}}$ & Very Good \\
\hline 2. & $\mathrm{Xi}+0,6 \mathrm{SBi}<\overline{\mathbf{X}} \leq \mathrm{Xi}+1,8 \mathrm{SBi}$ & Good \\
\hline 3. & $\mathrm{Xi}-0,6 \mathrm{SBi}<\overline{\mathbf{X}} \leq \mathrm{Xi}+0,6 \mathrm{SBi}$ & Fair \\
\hline 4. & $\mathrm{Xi}-1,8 \mathrm{SBi}<\overline{\mathbf{X}} \leq \mathrm{Xi}-0,6 \mathrm{SBi}$ & Poor \\
\hline 5. & $\overline{\mathbf{X}} \leq \mathrm{Xi}-1,8 \mathrm{SBi}$ & Very Poor \\
\hline
\end{tabular}

Note: $\mathrm{Xi}=\frac{\mathbf{1}}{\mathbf{2}}($ ideal $\max$ score + ideal $\min$ score $) ; \mathrm{SBi}=\frac{\mathbf{1}}{\mathbf{6}}($ ideal max score - ideal min score $) ; \overline{\mathbf{X}}=$ average score of media quality.

\section{RESULTS AND DISCUSSION}

Multimedia of Chemistry Enrichment in Colloidal Systems was developed for Vocational High School Students. The multimedia can be operated on the laptop or personal computer (PC) and can be used for learning both inside and outside school. The multimedia was developed using the Adobe Flash Professional CS 6 program. The product was packaged in compact disk with application (.exe) format.

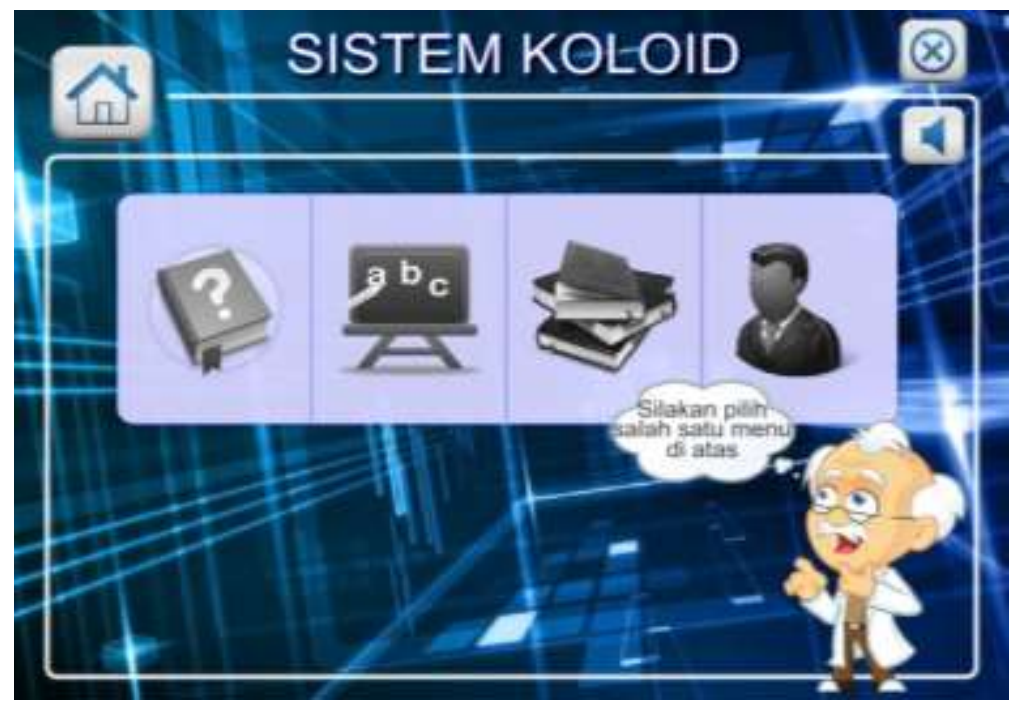

Figure 1 The Home Page of Multimedia

The multimedia home page consists of four menus: the instruction menu, the main menu, the references, and the profiles of developer. The home page of multimedia can be seen in Figure 1. The main menu consists of (1) a summary of the colloidal system equipped with images or animations, (2) the application of colloidal systems in daily life, in the fields of health, industry and agriculture which each field consists of 2-5 instances, some of which were equipped with animations or video, (3) profiles of scientists in colloidal systems and their exemplary traits, and (4) glossary. Screen capture of sample of multimedia content can be seen in Figure 2.

The result of research study showed that there were some advantages of this chemistry enrichment multimedia; (1) the material became more interesting and interactive, (2) it was easy to operate and could run on personal computers (PC) or laptops, (3) it was equipped with animation and video so that the explanations shown were easily understood, (4) it loaded the exemplaries from chemistry figures which could motivate learners to emulate the values of those figures. 
The enrichment multimedia was easy to operate. The difference in specification of PC or laptop, however, can affect the smooth operation of this multimedia. Not all explanations in multimedia equipped with animation or video. This also multimedia had not been tested to students, so the effect of multimedia of chemistry enrichment to students had not known yet.

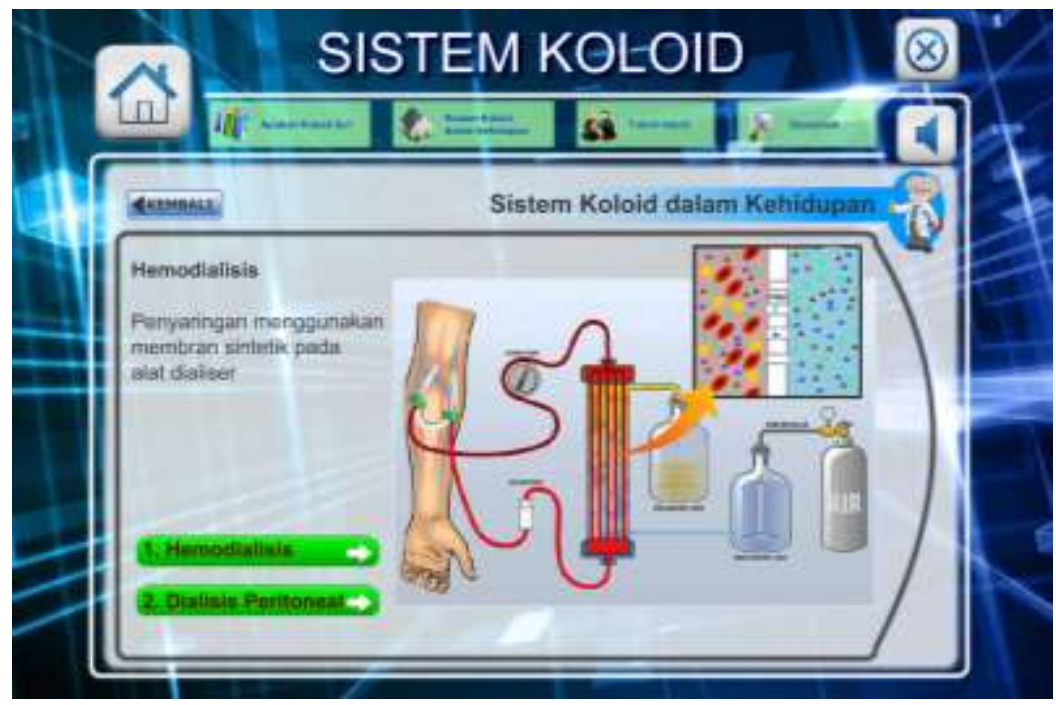

Figure 2 Sample of Multimedia Content

The initial product of multimedia were reviewed by content experts, media experts, and three peer reviewers. Peer reviewers gave suggestion and correction on the text, appearance, and programming. Content expert reviewed the content feasibility and language aspect. Feedback from content experts included content, choice of words and images, as well as the suitability of animations in multimedia towards the material. Meanwhile, the media expert reviewed the visual-display of media, audio-display of media and media programming. The suggestion from media experts was about the effectiveness of navigation and media programming. Suggestion from content experts, media experts and peer reviewers was a data development process that was used to improve the initial multimedia product. Multimedia product that had been improved, then, were assessed by vocational school chemistry teachers.

The product were rated by five chemistry teachers of vocational high school who came from three different types of vocational school. The reviewers were health vocational school, agriculture vocational school, and technology and engineering vocational school teachers. Assessment by reviewers was based on six aspects of the criteria, including content feasibility, language, visual-display of media, audio-display of media, media programming, and expediency of the media. The results of multimedia assessment of each aspect can be seen in Table 2. Assessment results from reviewers were used to determine the quality of multimedia products, while the suggestion from the teachers was used to improve the final product of multimedia.

Table 2 Multimedia Quality Score of Each Aspect

\begin{tabular}{|l|c|c|}
\hline \multicolumn{1}{|c|}{ Aspect } & Average of Total Score & Category \\
\hline Content Feasibility & 26,4 & Very Good \\
\hline Language & 8 & Good \\
\hline Visual-display of Media & 29,2 & Good \\
\hline Audio-display of Media & 12 & Good \\
\hline Media Programming & 26,8 & Very Good \\
\hline Expediency of the Media & 9,4 & Very Good \\
\hline
\end{tabular}


Content in instructional media must be accurately $[15,16]$ and contain educational value [15]. The content feasibility aspect consisted of six indicators covering material conformity with curriculum; material conformity with learning objectives; accuracy of content; image, animation and video conformity; completeness of information on images and animations; and the suitability of the samples. The score of content feasibility aspect was obtained 26.4 from a maximum score of 30 . Based on the score, the content feasibility was categorized as very good. Compared with the maximum score in this aspect, the percentage of idealization was $88 \%$.

The content in this multimedia conforms to the learning objectives and basic competencies for the material of the colloidal system. In Vocational high school, chemistry is included in the group of basic subjects in the field of expertise [16]. The chemistry materials given in the vocational school must be suitable with their area of expertise. Furthermore vocational students were engaged in explore new concept that were relevant to their daily life experience [9]. Application of colloidal systems in daily life, in the fields of health, industry and agriculture in this multimedia simulate interest of student since they realize that chemistry material is relevant and could be support their vocational field [4]. The material presented in this multimedia was also not deviant, although in some parts, there was still a writing error. The images, animations, videos, and examples included were compatible with the material. Previous research found that students who learn used animation in multimedia instruction gained higher understanding at the molecular level [10], so animations with narration were added in the multimedia to help visualize the abstract object become easier to understand.

The language aspect consists of two indicator points. These indicators include the use of standard language and the use of communicative language. The average score obtained on the language aspect was 8. The score met the criteria of good quality. Compared with the ideal maximum score on this aspect, 10 , the percentage of idealization was $80 \%$. Both indicators on the language aspect could not achieve very good quality because there were still some writing errors. Materials in learning media should be easy to understand [17], but in the developed multimedia still there were words that were not common so that some reviewers did not understand the meaning of the word. In addition, presenting the material in a standard language as well as communicative according to the author was quite difficult.

The average score of the visual-display of media aspect was 29.2 from a maximum score of 35 . The score was in the good category with the ideal percentage of $83.43 \%$. This aspect consisted of seven indicators including the presentation of interesting material; the suitability of background, the suitability of color proportions; the layout of text and images, the composition of color and form of writing; readability of the text, and the quality of images, animations, and videos. Learning media should be able to attract students' attention [17]. Content in this multimedia was not only in the form of text and images, but also animation and video equipped with narration in order to make the content more interesting and not boring. In addition, the presence of visual and audio elements in multimedia could involve the sense of sight and hearing simultaneously. The quality of images, animations, and videos that exist in this multimedia was also rated very good. In general, images, animations, and videos used already had a high resolution that was not broken or blurred. The background used had a neutral color to match the colors of the text, images and animations. Layout of text and images and the composition of color and form of writing generally was good. The color of writing was contrasted with the background color, while the selected writing form was clear and uncomplicated. Readability of writing was also rated good because the size of the letters used was adjusted, but in this indicator the size of personal computer (PC) and laptop greatly affect. If the PC or laptop used was small, then the multimedia size would also adjust so that the readability level of writing would be reduced.

There were three indicators on the aspect of audio-display of media, including the clarity of narration, the suitability of the type of sound effect, and the suitability of the back sound. The score obtained on the audio-display of media aspect was 12 . The score met the good quality criterion with an $80 \%$ percentage of ideality. In general, the narration in multimedia was good enough, beheading and intonation were also adjusted to be easy to understand. Narrations were are added to make animations more easily understood, 
because of narration and animation transfer information better that animation and on-screen text [8]. However, due to the limitations of devices owned by developers, the resulting narrative volume was weak. Background music draws more attention of students [18]. The sound effects and back sound were designed so as not to interfere with concentration, but the volume was loud enough so it was a bit annoying when the narration was played. Actually there is button controlled the background music to on or off, however, the reviewers suggested to add control button that can control the volume of the background music.

The programming which consisted of the ease of opening and closing the multimedia, clarity of multimedia usage guidelines, navigation effectiveness, smooth operation, ease of menu selection, and ease of running animation meets the very good criteria. The average score obtained of this aspect was 26.8 from maximum score of 30 . The percentage of ideality of this aspect was $89.33 \%$. This multimedia used navigation structure that allowed users to run multimedia freely. Users could go directly to the previous menu without having to go back to the previous page, even go to the main menu without having to return the previous menu. It could facilitate the operation, for example, when using a material to learn one and then find the term that was not understood, the user could go directly to the glossary menu to find the term understanding. In general, navigation in this multimedia was effective, although still found one part that error navigation.

The last aspect was expediency of the media. The aspect consists of two indicators i.e. can be used as self-learning media and can simulate the interest of students. That aspect was also in a very good category with an ideal percentage of $94 \%$. The average score obtained in this aspect was 9.4 from maximum score of 10. One of the criteria of multimedia is to be able to motivate and interest the students [16]. Reviewers considered that the enrichment multimedia was very useful as an independent learning media and could stimulate the motivation of learners. That was appropriate with previous research that student who use animated movie in multimedia developed higher motivation to learn science [9].

Aspect of expediency had the highest percentage of ideality that was $94 \%$. The aspect of expediency had the highest ideality because the reviewer considered the multimedia could be used for self-learning media of students. In addition, the resulting multimedia was also equipped with animations, videos, and narrations that were considered interesting so that it could stimulate the interest of students. Aspects of language and audio-display of media got the lowest percentage of ideality that was $80 \%$. The language aspect got the lowest percentage of ideality because in multimedia there were some writing errors in some parts. While the audio-media aspect was sometimes a bit annoying when the narration was running. Comparison of percentage of adulthood of each aspect of assessment can be seen in Figure 3 .

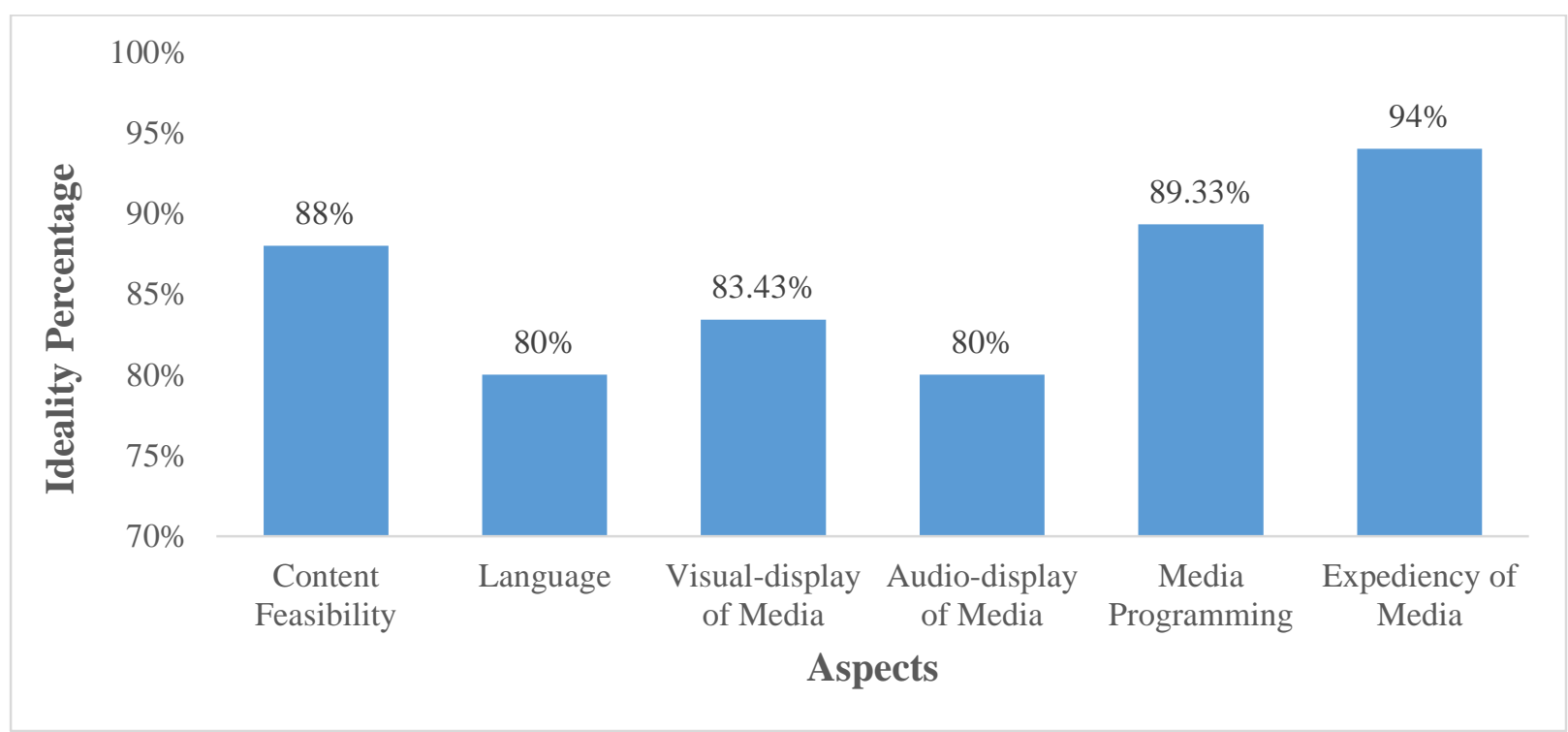

Figure 3 Comparison of ideality percentage of each aspect 
Overall the average of multimedia product score was 111.8. The score was included in the category of very good with the ideality percentage of $86 \%$. The six aspects of assessment in the instrument of multimedia quality assessment got a good predicate which meant that it was the least predicate among other aspects. The results of the assessment indicatated that the products were ideal as an enrichment media of colloidal systems for vocational high school students.

\section{CONCLUSION}

Multimedia of chemistry enrichment in colloidal systems was developed for Vocational High School students. The multimedia can be operated on the laptop or personal computer (PC) and can be used for learning both inside and outside school. The multimedia consists of a summary of the colloidal system equipped with images or animations, the application of colloidal systems in daily life, in the fields of health, industry and agriculture which were equipped with animations or video, profiles of scientists in colloidal systems and their exemplary traits, and glossary.

In general, the multimedia assessment score was included in the category of very good category. Analysis on each aspect shows that content feasibility, media programming, and expediency of the media aspects was included in the very good category, while language, visual-display of media, audio-display of media aspects included in the good category. These results indicatated that the products were ideal as an enrichment media of colloidal systems for vocational high school students.

\section{ACKNOWLEDGEMENTS}

Thank you to Mrs. Endang Dwi Siswani for guidance in this research.

\section{REFERENCES}

[1] Menteri Pendidikan dan Kebudayaan Republik Indonesia. (2013). Peraturan Menteri Pendidikan dan Kebudayaan Republik Indonesia Nomor 70 Tahun 2013 tentang Kerangka Dasar dan Struktur Kurikulum SMK/MAK,.

[2] Devi, A. A., Saputro, S., Saputro A. N. C. (2014). Jurnal Pendidikan Kimia, 3, 45-50.

[3] Haryanti, Wiyarsi, A. (2017). Prosiding Seminar Nasional UNY, 67-74.

[4] Boddey, K., Berg, K. D. (2015). Chemistry Education Research and Practice, 16, 212-227.

[5] Arsyad, A. (2004). Media Pembelajaran, PT Grafindo Persada.

[6] Daryanto. (2010). Media Pembelajaran: Peranannya Sangat Penting dalam Mencapai Tujuan Pembelajaran, Gava Media.

[7] Dale, E. (1946). Audio-Visual Methods in Teaching, Dryden Press.

[8] Mayer, R. E. (2002). The Psychology of Learning and Motivation, 41, 85-139.

[9] Barak, M., Ashkar, T., Dori, Y. J. (2011). Computer \& Education, 56, 839-846.

[10] Ardac, D., Akaygun, S. (2004). Journal of Research in Science Teaching, 41(4), 317-337.

[11] Borg, W. R., Gall, M. D. (1983). Education Research: An Instruction, Longman Inc,.

[12] Angelina, G. (2013). Undergraduate Thesis, Universitas Pendidikan Indonesia.

[13] Susanto, E. (2013). Unpublished Undergraduate Thesis, Universitas Negeri Yogyakarta.

[14] Widoyoko, E. P. (2011). Evaluasi program pembelajaran, Pustaka Pelajar, Winters,.

[15] Squires, D., \& Preece, J. (1996). Computers Education, 27(1), 15-22.

[16] Leacock, T. L., Nesbit, J. C. (2007). Educational Technology \& Society, 10 (2), 44-59.

[17] Oyelekan, O. S., Olorundare, A. S. (2009). International Journal of Education and Development using Information and Communication Technology, 5(2), 88-104.

[18] Lutz Jäncke, L., Sandmann, P. (2010). Behavioral and Brain Functions, 6(3), 1-14. 